\title{
Effect of Tuna Based Formulated Diet on Growth and Play Behaviour of Domestic Cats
}

\author{
N. Abeysinghe and H.N.N. Dilrukshi*
}

\begin{abstract}
Feline diet plays a vital role in growth and behaviour of cats. The amount of Taurine (an essential amino acid) in the diet is a limiting factor for growth and the high cost of commercial feline feeds is a problem especially in developing countries. The objectives of the study were to formulate a cat diet using locally available cheaper ingredients and to evaluate its effect on growth rates, skin/coat conditions, activity levels based on play behaviour (social play and object play) of cats and sensory attributes for cat faeces. The key ingredient of the formulated diet was tuna as it enriched with the Taurine requirement of feline. Eight weaned domestic kittens were tested as two groups fed with two diet types; formulated and commercial, independently. Sensory attributes of faecal samples, skin and coat, periodic weights, social and individual behaviours were monitored. The growth rate of the kittens of two diet groups showed that there was no significant difference $(p>0.05)$. The sensory test showed that the faeces from commercial diet group had stronger odours $(\mathbf{p}<0.05)$ and darker colours $(p<0.05)$. The texture of the faeces and sensory attributes of skin/coat did not show significant differences (p>0.05). All social play behaviour types for two diet groups were significantly different $(p<0.05)$ and, the felines from the formulated diet group showed higher frequency in play behaviour. Formulated diet group had significantly $(p<0.05)$ higher activity rates for arching and stalking. Commercial diet fed group cried more often compared to the
\end{abstract}

\footnotetext{
Department of Livestock and Avian Sciences, Faculty of Livestock, Fisheries and Nutrition Wayamba University of Sri Lanka, Gonawila 60170, Sri Lanka

*hnndilrukshi@gmail.com
}

formulated diet group. Thus, the formulated diet comprises a balanced nutritional profile that meets the normal growth rates of felines and satisfying activity levels for the cats.

Keywords: Formulated diet, Growth, Kittens, Play behaviour, Tuna fish

\section{INTRODUCTION}

Humans hold a long and complex history with cats. Since the domestication of feline, this bond has developed to a vast variety of forms at present. Companionship is the primary reason that links humans and cats. As essential components of pet care, along with health and medical attention, nutrition plays a vital role (Linda and Case, 2010). Cats' unique nutritional requirement differs with age, breed, gender, activity, temperament, environment and metabolism (NRC, 2006).

With regard to feeding cats, two options can be made; preparing a homemade diet, or purchasing a commercially prepared cat food. Commercial pet foods are classified under several categories. However, the general classification of commercial pet foods is based on the processing method, methods of preservation and moisture content. Based on moisture content, three categories of pet foods can be identified. They are, dry (6$10 \%$ moisture), semi-moist $(15-30 \%$ 
moisture), and wet (75\% moisture) foods (Linda and Case, 2010).

Cat feeds should fulfil the dietary requirements of feline to avoid nutritional deficiencies. The limited ability to synthesize Taurine in cats and insufficiency to compensate for the natural losses via the conjugated bile acid (Taurocholic acid) in the gastrointestinal tract make Taurine an essential nutrient for cats (Global Pet Food Market, 2014).

Major ingredients in a cat feed may contain major nutrients, and others may contribute several essential nutrients to the diet. Maize is considered as a primary source of digestible carbohydrate included in pet foods. Tuna fish contains high levels of protein and is a major protein source (Linda and Case, 2010). Tuna fish comprises $155 \mathrm{mg}$ of Taurine per $100 \mathrm{~g}$ that can fulfil the Taurine requirement of cats (AAFCO, 2009). Consequently, every ingredient contained within a commercial cat food is required to possess a specific purpose in fulfilling the nutritional requirements, palatability and pelletability (Linda and Case, 2010).

The feed should achieve the normal growth and development of growing cats. As the cats are obligatory carnivore, their diet should comprise high amounts of proteins with animal origin, digestible carbohydrates, fats, vitamins and minerals in correct proportions (Linda and Case, 2010), so called a "Complete" or "Balanced" diet.
The food affects not only the growth, but also it influences the play behaviour of cats (Bradshaw and Cook, 2008; Bradshaw et al., 2012). Play is easily recognized but it is difficult to define (Martin and Bateson, 1988). One formal definition for play is "all motor activity performed postnatally that appears to be a purposeless, in which motor patterns from another context may often be used in modified forms and altered temporal sequencing" (Bradshaw et al., 2012). The most applicable method to classify play behaviour is the entity towards which the cat leads such motor patterns (i.e. object play and social play that involve a conspecific) to another cat (Bradshaw et al., 2012). Object play and social play are two types of play behaviour. When food is in short supply, play can be dispensed. The young mammals who run out of proper nutrition do play less than when they are better fed (Bateson et al., 1990).

The cat foods in the market guarantee healthy growth and better socializing ability which occupy high reputation along with high costs. However, the low-income levels of the majority of people in developing countries such as Sri Lanka, cat foods are less in common. Therefore, this study was carried out to formulate an affordable cat feed, using locally available ingredients including tuna fish as the main ingredient, which meet the principal nutritional requirements and to compare the play behaviour of cats fed with the formulated diet and commercial diet. 


\section{METHODOLOGY \\ Experimental Set-Up}

The experimental animals were 6 weeks old eight weaned domestic kittens (Felis catus) who were in good health and of known weights and gender. Both groups had 1:1 male to female ratio. Kittens were randomly allocated to two groups, namely formulated diet group and commercial diet group. The pens were of $1.5 \times 1.5 \times 1.5 \mathrm{~m}^{3}$ in size. Each pen was confined with a litter-tray, food and water bowls. The temperature of the pens did not fall below $25{ }^{\circ} \mathrm{C}$. The kittens in two pens were not capable of seeing each other, but to some extent the auditory and olfactory contact was possible.

Before commencing the trial, kittens were assigned to pens and were fed with homemade diets for 7-days adjustment period. Both groups gained weight during this period. Afterwards, they were placed on the experimental feeding period of 82 days. Throughout the study, cats were fed either with commercial diet or formulated experimental diet to maintain body weight and body condition score. The daily intake was divided into three portions and animals were fed three times daily, at the same time each day; 9.00 a.m., 1.00 p.m. and 5.00 p.m. Water was always available in the pens. The excess food per each cage was weighed back after feeding at the end of each day.

\section{Preparation of Cat Feed}

The formulated diet was based on maize, rice bran, rice flour, wheat flour, animal fat, Di-Calcium Phosphate, egg, soybean meal, and dried tuna fish meal and was formulated to contain moderate concentrations of nutrients according to the Association of American Feed Control Officials (AAFCO, 2009) and the National Research Council (NRC, 2006) guidelines.

Dried tuna fish meal was the major ingredient for cat feed formulation. To prepare it, raw tuna fish was steamed for 30 min and was subject to expel oil using an oil expeller. Oil expelled tuna was oven dried at $60{ }^{\circ} \mathrm{C}$ for $48 \mathrm{~h}$ followed by grinding to obtain a fine powder.

To prepare the formulated diet, the raw ingredients were mixed and pelletized in a pelletizing machine. The pellets were steamed for $30 \mathrm{~min}$, followed by oven drying for $1 \mathrm{~h}$ at $60{ }^{\circ} \mathrm{C}$. The pellets were then ready to be consumed by the felines (Figure 1).

\section{Proximate Analysis of Feed Formulation}

Proximate analysis test for the formulated feed and commercial feed samples was carried out for energy level, crude protein, crude fat, crude fibre, moisture and ash contents. Bomb calorimetric method was used for energy evaluation (Miller and Payne, 1959); Kjeldahl method was used to analyse the crude protein (Bradstreet, 1954); solvent extraction method was employed for crude fibre analysis (Thiex et al., 2003), and oven dry method was used for analysing moisture content. Ash content was determined by the muffle furnace method. 


\section{Growth Measurements of Cats}

Kittens were weighed at 4-day intervals from $8^{\text {th }}$ week to $18^{\text {th }}$ week. The weights were taken to the nearest $5 \mathrm{~g}$.

\section{Ingredients}

(Maize, Rice bran, Rice flour, Wheat flour, Animal fat, Di-Calcium Phosphate, Egg, Soybean Meal, and Dried tuna fish meal)

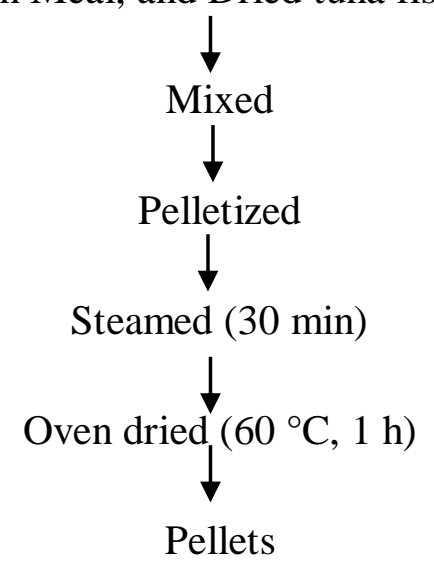

Figure 1. Procedure for preparation of cat feed formulation

\section{Sensory Evaluation for Skin and Coat}

Skin and coat sensory evaluation was performed for eight individual kittens for attributes of gloss, softness, optimum coat feel and scale of the skin and coat. For each attribute, a 5-point scale from the best to worst was used: best $=1$, better $=2$, moderate $=3$, less than moderate $=4$ and worst $=5$. Thirty untrained panellists examined each kitten.

\section{Sensory Evaluation of Faecal Samples}

Faecal samples from the two groups were evaluated for three attributes by 30 untrained panellists. The attributes evaluated were texture, colour and odour, using a 5-point scale. The scores for texture of faeces; 1 = hard pellet form, 2 = hard, formed, dry stools that remain firm and soft, $3=$ soft, formed, moist stools that remain its shape, $4=$ soft, unformed stools that assume the shape of container and pudding-like, and $5=$ watery liquid stools that can be poured. Stool colour were scored as; 1 = pale, $2=$ light yellow, 3 = yellow to brown, $4=$ dark brown and $5=$ black. For odour of stools; 1 = odourless, 2 = slight odour, 3 = moderate odour, $4=$ bad odour and $5=$ strong bad odour.

\section{Play Behaviour of Cats}

Play behaviour was evaluated in terms of social play (Caro, 1981) and object play (Bateson and Young, 1981). Observations were made, separately for the two groups, 2 - $4 \mathrm{~h}$ after feeding.

\section{Social Play}

During the $14^{\text {th }}-18^{\text {th }}$ week of age the four kittens of each group were separately placed in an observation cage $\left(1.5 \times 1.5 \times 1.5 \mathrm{~m}^{3}\right)$ once a week. The behaviours were recorded for a duration of $40 \mathrm{~min}$ each week. Cat behaviour was scored constantly focusing on individual animal basis in the video / focal animal method. Every single cat was observed for $30 \mathrm{~s}$, while an individual directed its behaviour patterns each time they occurred towards other cats. In a systematic pre-determined manner, the observation was transferred to the next cat in each 30 s. During each session, each cat 
was observed for $10 \mathrm{~min}$.

Since the interactions between kittens were typically dyadic, the behaviour patterns showed by kittens directing towards each other were noted down together with the recipient of such actions. Behavioural events lasted for an extremely short duration. In the meantime, 18 behaviour types were evaluated for social play behaviour and were defined as mentioned in the ethogram (Table 1). Relative frequencies of each behaviour pattern were calculated for every week by dividing the number of times a behaviour occurred by the number of minutes that the cat was watched. Mean scores were calculated for the two groups. Only the behaviour directed by kittens towards others was used in the analysis.

\section{Object Play}

Observations were recorded at every 2 - 3 days interval between $14^{\text {th }}-18^{\text {th }}$ week of age. Two groups were watched on the same day interchanging the order of watching of groups. The observations for object play were made in their cages. Three play objects were recorded in each cage 2 - $4 \mathrm{~h}$ after feeding at the beginning of each session. The objects were a ball ( $3.5 \mathrm{~cm}$ diameter), a soft toy $\operatorname{dog}(12 \mathrm{~cm}$ length $\mathrm{x} 5.5 \mathrm{~cm}$ diameter) and a stuffed piece of cloth (10 $\mathrm{cm}$ length $\mathrm{x} 5.5 \mathrm{~cm}$ diameter). The periods of observation on each kitten in pen lasted for $15 \mathrm{~min}$. A video record was taken of each cat when playing. A check sheet was used to record the frequencies of nine categories (Table 2) of playful activities per minute.

Inactivity was calculated as seconds per minute. Records for each observation were taken per kitten and the frequencies were taken of each activity type. Relative frequencies of these behaviour patterns were calculated for each day by dividing the number of times a behaviour occurred by the number of minutes the cat was watched. Mean scores per day were calculated for the two groups.

\section{Experimental Design and Statistical Analysis}

Eight kittens were randomly distributed in 1:1 male to female ratio into two groups, formulated diet group and commercial diet group. Experiment was arranged in a completely randomized design. Results of skin and coat sensory evaluation and faecal sensory evaluation were analysed by Friedman test and Kruskal-Wallis Test, respectively using Minitab (version 15.0) software. Growth rates of two groups were analysed using a t-test while the play behaviours were analysed using a ChiSquare test. In every test, $95 \%$ of confident level was used.

\section{RESULTS AND DISCUSSION Nutritional Standards of Feed Formulation}

Nowadays, the pets, especially cats and dogs, play a significant role as pet animals providing psychological and physiological benefits in human life (Global Pet Food Market, 2014). Pet owners have become 
Table 1. Ethogram for the social behaviour types of cats

\begin{tabular}{|c|c|}
\hline Behaviour & Description \\
\hline Paw & Bringing the forepaw into contact with a cat \\
\hline Hold & Bringing forepaws or forearms simultaneously into contact with a cat \\
\hline Rolled contact & Lying on dorsal or lateral surface and employing any contact pattern \\
\hline Bite & Bringing jaws into contact with a cat and closing them \\
\hline Chase & Running after a moving cat \\
\hline Rear & Standing or vertical leaping on hind legs with forelegs raised and splayed \\
\hline Flee & Running while being followed by a moving cat \\
\hline Paws up & $\begin{array}{l}\text { Front paws, and sometimes back paws as well, held up to but not touching } \\
\text { another cat, while subject is in a rolled position }\end{array}$ \\
\hline Canter & $\begin{array}{l}\text { Jerky running gait during which all paws repeatedly and simultaneously } \\
\text { leave the ground; head and tail often held high }\end{array}$ \\
\hline Attack & Jump on to a cat and grasp it with forepaws or forelegs \\
\hline Crouch & $\begin{array}{l}\text { Belly on the ground with all limbs by the side of the body, oriented and } \\
\text { attentive to a con- specific; back legs often treading }\end{array}$ \\
\hline Arch & $\begin{array}{l}\text { A marked upward bending of the spine while still standing, leaping upwards } \\
\text { or moving sideways, with or without piloerection }\end{array}$ \\
\hline $\begin{array}{l}\text { Four paw } \\
\text { contact }\end{array}$ & $\begin{array}{l}\text { Contacting another cat with one or two back paws or back legs, e.g. stepping } \\
\text { on, kicking once or repeatedly kicking with back legs in unison }\end{array}$ \\
\hline Foot contact & $\begin{array}{l}\text { Contacting another cat with one or two back paws or back legs, e.g. stepping } \\
\text { on, kicking once or repeatedly kicking with back legs in unison }\end{array}$ \\
\hline Paws up & $\begin{array}{l}\text { Front paws, and sometimes back paws as well, held up to but not touching } \\
\text { another cat, while subject is in a rolled position }\end{array}$ \\
\hline Face-off & $\begin{array}{l}\text { Sitting next to another cat, often with tail lashing and head twisting; recipient } \\
\text { in a rolled position or similar face off stance }\end{array}$ \\
\hline Stand-off & $\begin{array}{l}\text { "Standing next to another cat, often with head twisting; recipient usually in } \\
\text { a rolled position, these latter two patterns usually preceded an attack }\end{array}$ \\
\hline Approach & Movement of any sort (excluding canter) towards another cat \\
\hline
\end{tabular}

more concerned about the health and wellbeing of their pets. This growing bond and the rising pet health concern is the basis to increase pet food sales and demand in the pet food industry (Global Pet Food Market, 2014).

Increased consumer awareness of the benefits of quality pet food also drives the growth in emerging markets (Pathfinder Report, 2010). The increasing demand for cat feed was a motive in carrying out this study with a view to formulate a palatable cat feed at a lower price, using locally available feed ingredients, to meet the main nutritional requirements of cats. The proximate compositions of the dried tuna fish meal and formulated cat feed are 
Table 2. Ethogram for the object play behaviours of cats (Bateson and Young, 1979; 1981)

\begin{tabular}{|c|c|}
\hline Behaviour & Description \\
\hline $\begin{array}{l}\text { Object } \\
\text { contact }\end{array}$ & $\begin{array}{l}\text { Each pat with a paw making } \\
\text { contact with an object } \\
\text { (particularly the toy dog, } \\
\text { ball or stuffed rabbit) and } \\
\text { each bite of these objects }\end{array}$ \\
\hline Rake & $\begin{array}{l}\text { Each bout of kicking } \\
\text { movements at another cat or } \\
\text { at an object with one or both }\end{array}$ \\
\hline Stalk & $\begin{array}{l}\text { Each bout of low crouching } \\
\text { with hind legs. Treading or } \\
\text { creeping or running briefly } \\
\text { belly close to the ground } \\
\text { and head low towards } \\
\text { another object }\end{array}$ \\
\hline Arch & $\begin{array}{l}\text { Each occurrence of a } \\
\text { marked upward curving of } \\
\text { the spine while standing } \\
\text { still, leaping upwards, or } \\
\text { moving sideways. The } \\
\text { orientation is usually side } \\
\text { on to another cat or object }\end{array}$ \\
\hline $\begin{array}{l}\text { Hold } \\
\text { object }\end{array}$ & $\begin{array}{l}\text { Each occurrence of } \\
\text { grasping an object between } \\
\text { the lower parts of the } \\
\text { forelimbs }\end{array}$ \\
\hline Cry & $\begin{array}{l}\text { Each mew call given by a } \\
\text { kitten. This call is } \\
\text { seemingly given in distress } \\
\text { and is a non-playful } \\
\text { behaviour }\end{array}$ \\
\hline Inactivity & $\begin{array}{l}\text { Each } 30 \text {-s period when the } \\
\text { kitten spends the whole } \\
\text { period either lying still with } \\
\text { its eyes closed or almost } \\
\text { closed }\end{array}$ \\
\hline
\end{tabular}

presented in Table 3. It shows that the formulated diet meets the Association of American Feed Control Officials (AAFCO, 2009) standards in terms of energy level, crude protein, crude fat and crude fibre contents (Table 3). The AAFCO sets regulations for the manufacturing of pet animal feeds. The results of proximate analysis (Table 3) thus reveal that the formulated diet has met the required nutrient contents that should be processed by cat feed.

\section{Growth Performance of Cats}

The initial weights of two diet groups are shown in Table 4. Initial mean weights of the two diet groups showed no significant difference $(p>0.05)$. Results also showed that the mean growth rates of the two diet groups were not significantly different throughout the experimental period ( $>00.05$; Figure 2). In both groups the mean growth rates decreased from day 5 - day 7 and increased from day 8 onwards (Figure 2). The growth performance of kittens, starting from the initial weights till the end, in terms of weight gain was not significantly different between two diet groups. This could be attributed to similar nutritional profiles of the formulated and commercial feeds.

\section{Skin, Coat and Faecal Sensory Attributes}

Certain essential nutrients support healthy skin and coat of cats and must therefore, be regularly included in the diet in adequate levels. Linoleic acid in the diet helps lubricate skin and hair and enhance coat 
Table 3. Proximate compositions of dried tuna fish meal and the formulated feline feed

\begin{tabular}{|c|c|c|c|}
\hline Component & $\begin{array}{c}\text { Dried tuna } \\
\text { fish meal }\end{array}$ & $\begin{array}{c}\text { Formulated } \\
\text { feed }\end{array}$ & $\begin{array}{c}\text { AAFCO } \\
\text { standard }^{2}\end{array}$ \\
\hline Energy (kcal ME/ kg DM) ${ }^{1}$ & 2850 & 3500 & $3500-4000$ \\
\hline Crude protein (\% per DM) & 50 & 21 & $20-21$ \\
\hline Crude fat (\% per DM) & 10 & 11.53 & $7.8-28$ \\
\hline Crude fibre (\% per DM) & - & 3 & $0-5$ \\
\hline
\end{tabular}

${ }^{1} k c a l$ per metabolizable energy per $\mathrm{kg}$ of dry matter of the diet.

${ }^{2}$ AAFCO - Association of American Feed Control Officials; DM - Dry Matter

shine. In addition, the antioxidant nutrients, Vitamins A, D and E support and maintain healthy skin cells (Linda and Case, 2010). Since cats are reared for affection, people expect them to have glossy and soft skin.

Sensory evaluations for cat skin and coat of the two groups revealed that there was no significant difference $(\mathrm{p}>0.05)$ with regard to all four attributes $(\mathrm{P}$ values for skin and coat sensory: Gloss: $\mathrm{p}=0.317$, Softness: $\mathrm{p}=0.317$, Optimum coat feel: $\mathrm{p}=$ 1.000, Scale: $p=1.000$; Figure 3).

Table 4. Initial weights of the two feline groups

\begin{tabular}{lc}
\hline \multicolumn{1}{c}{ Treatment } & $\begin{array}{c}* \text { Mean initial } \\
\text { weight of feline }(\mathbf{g})\end{array}$ \\
\hline & \\
Formulated diet & 449.50 \\
Commercial diet & 414.00 \\
\hline *P value $=0.3781$ &
\end{tabular}

The non-significant differences between formulated diet group and commercial diet group with respect to all four attributes of gloss, softness, optimum coat feel and scale indicates that the formulated diet has the same influence as the commercial diet on the skin and coat of cats.

The cat faecal sensory was based on some of the common features of faeces such as texture, colour and odour. The mean scores obtained for each attribute of faecal sensory evaluation of the two diet groups are shown in Figure 4. There was no significant difference $(p>0.05)$ in the texture of faeces among the two diet groups. However, there was a significant difference in odour and colour $(\mathrm{p}<0.05)$ among the two groups ( $\mathrm{P}$ values for faecal sensory: Texture: $\mathrm{p}=0.1390$, Odour: $\mathrm{p}=0.0001$, Colour: $p=0.000)$. Faeces from the commercial diet group had a significantly stronger odour compared to that of the formulated diet group. If the diet is made of high protein and low carbohydrates cat faeces are likely to make strong odours (Linda and Case, 2010).

As such, the strong odour of cat faeces could possibly be caused by the commercial diet consisting of higher levels of proteins and lower levels of carbohydrates compared to the formulated diet. Moreover, faeces 
from the commercial diet group were significantly darker compared to that of the formulated diet group. If the cats were dehydrated, the stools would turn into darker colours (Linda and Case, 2010). Therefore, when the cats are fed with a commercial diet, they should be encouraged to consume more water. Results from the cat faecal sensory shows that if the cats were fed with the formulated diet, they often produced less odorous and light colour faeces keeping the cats more hydrated compared to the cats fed with the commercial diet.

\section{Play Behaviour of Cats}

Humans prefer to keep cats that are more playful, active and affectionate. Therefore, it is one of the major concerns in this study to measure activity levels of the kittens in terms of social play and object play.
Furthermore, these play types are correlated with the cats' feeding and predatory behaviour in the wild (Bradshaw et al., 2012).

Figures 5, 6, and 7 show the social play behaviour of cats from the two diet groups in each specified play type. All social behaviour categories showed significant differences between the diet groups $(\mathrm{p}<0.05)$.

Felines from the formulated diet category showed significantly higher mean frequencies of behaviour per minute for the social behavioural categories of paw, hold, bite, rolled contact, rear, chase (Figure 5), flee, canter, attack, arch, crouch, four paw contact (Figure 6), foot contact, mouth pen, paws up and stand-off (Figure 7) compared to the commercial diet group.

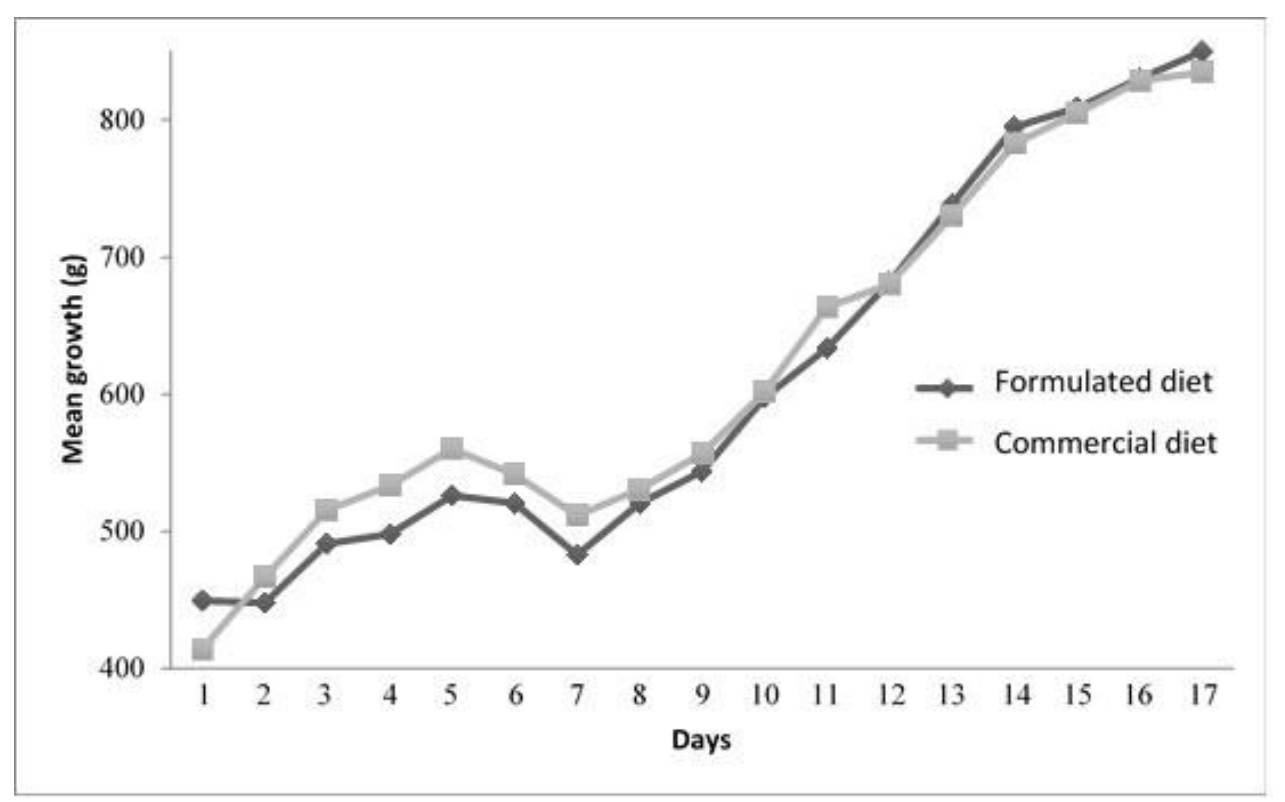

Figure 2. Mean growth rates of cats fed with the formulated diet and commercial diet 


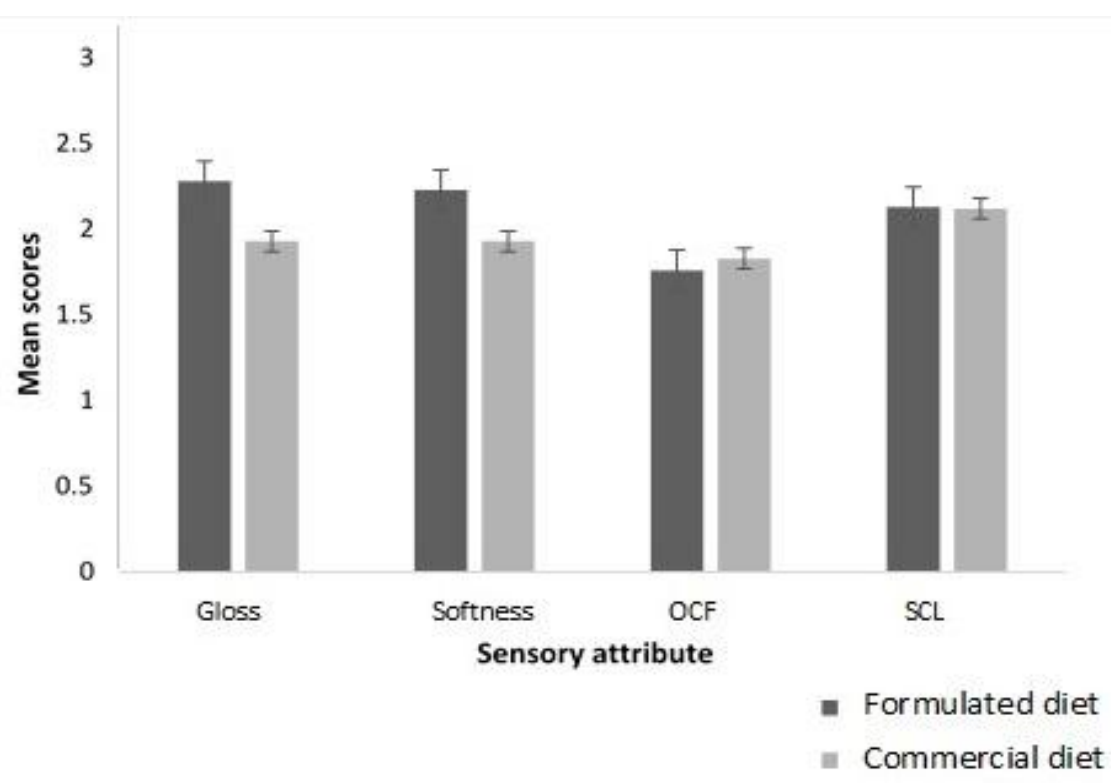

Figure 3. Mean scores for skin and coat sensory attributes of the cats fed with formulated diet and commercial diet.

OCF - optimum coat feel. SCL - scale, Gloss: $p=0.317$, Softness: $p=0.317$, OCP: $p=1.000$, Scale: $p=1.000$

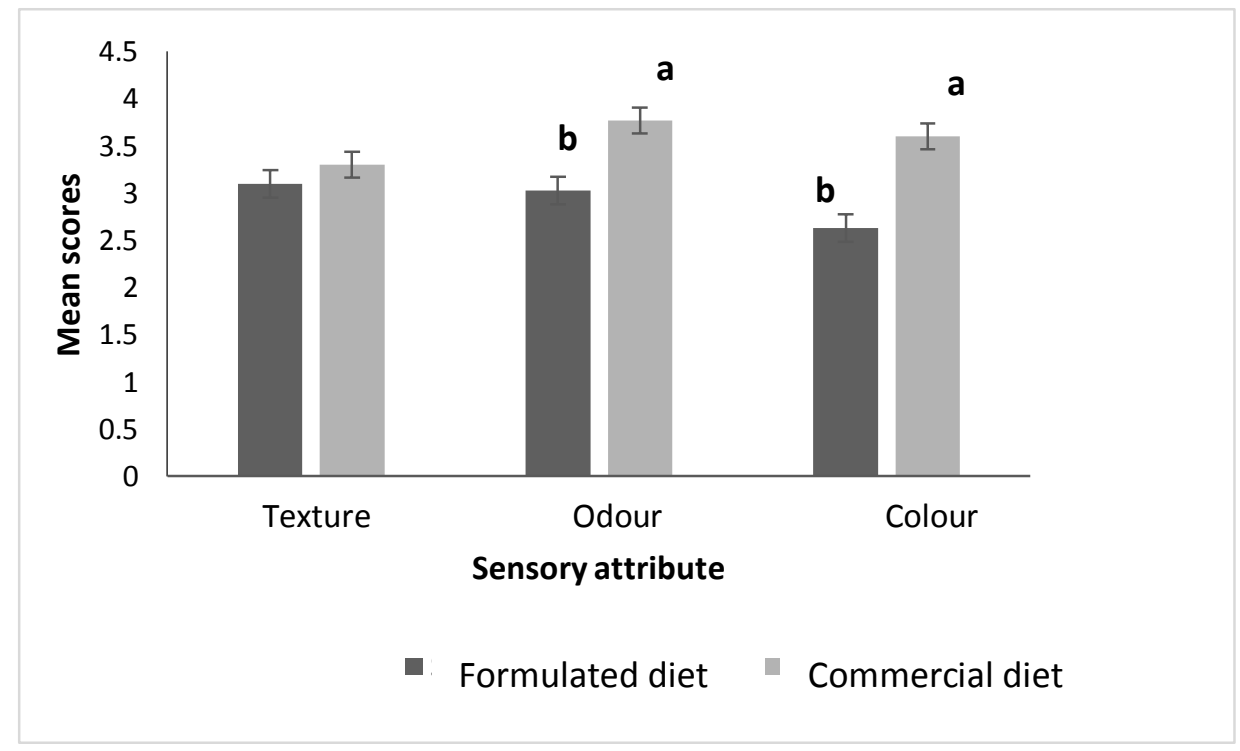

Figure 4. Mean scores for faecal sensory attributes of cats fed with formulated diet and commercial diet

${ }^{\mathrm{a}, \mathrm{b}}$ Different letters indicate significant differences $(p<0.05)$.

The formulated diet group showed higher social play levels over the commercial diet group in most of the play types. For the face-off behaviour category, 
the felines from commercial diet category showed significantly higher mean frequencies of behaviour per minute (on day
1) in comparison to felines from the formulated diet group (Figure 7).

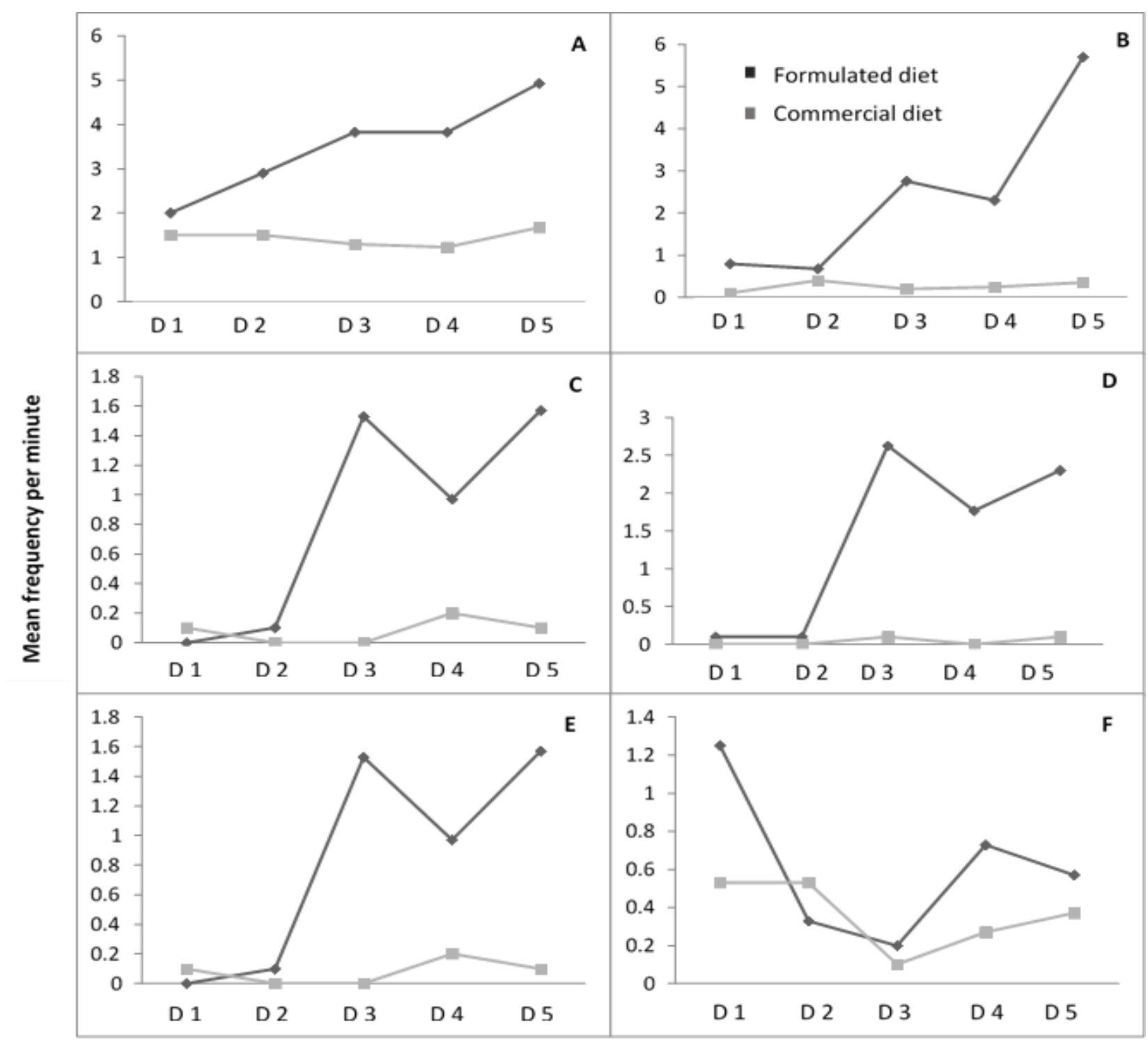

Time ( $\mathrm{D}$ = Days)

Figure 5. Social behaviour of cats fed with formulated diet and commercial diet $A=$ Paw $B=$ Hold, $C=$ Bite, $D=$ Rolled contact, $E=$ Rear and $F=$ Chase 
N. Abeysinghe and H.N.N. Dilrukshi

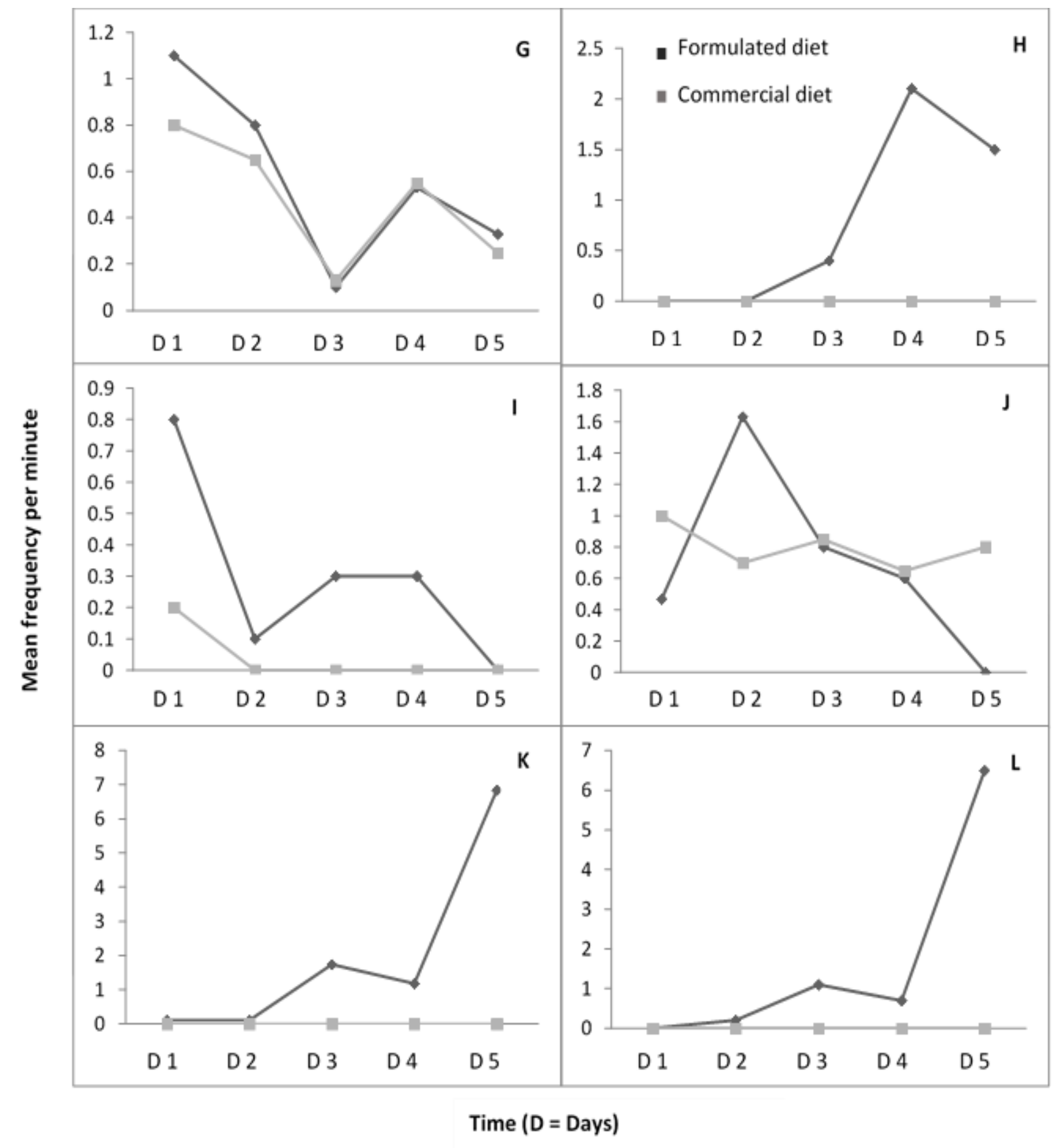

Figure 6. Social behaviour of cats fed with formulated diet and commercial diet $G=$ Flee, $H=$ Canter,$I=$ Attack, $J=$ Arch contact,$K=$ Crouch and $L=$ Four paw contact 


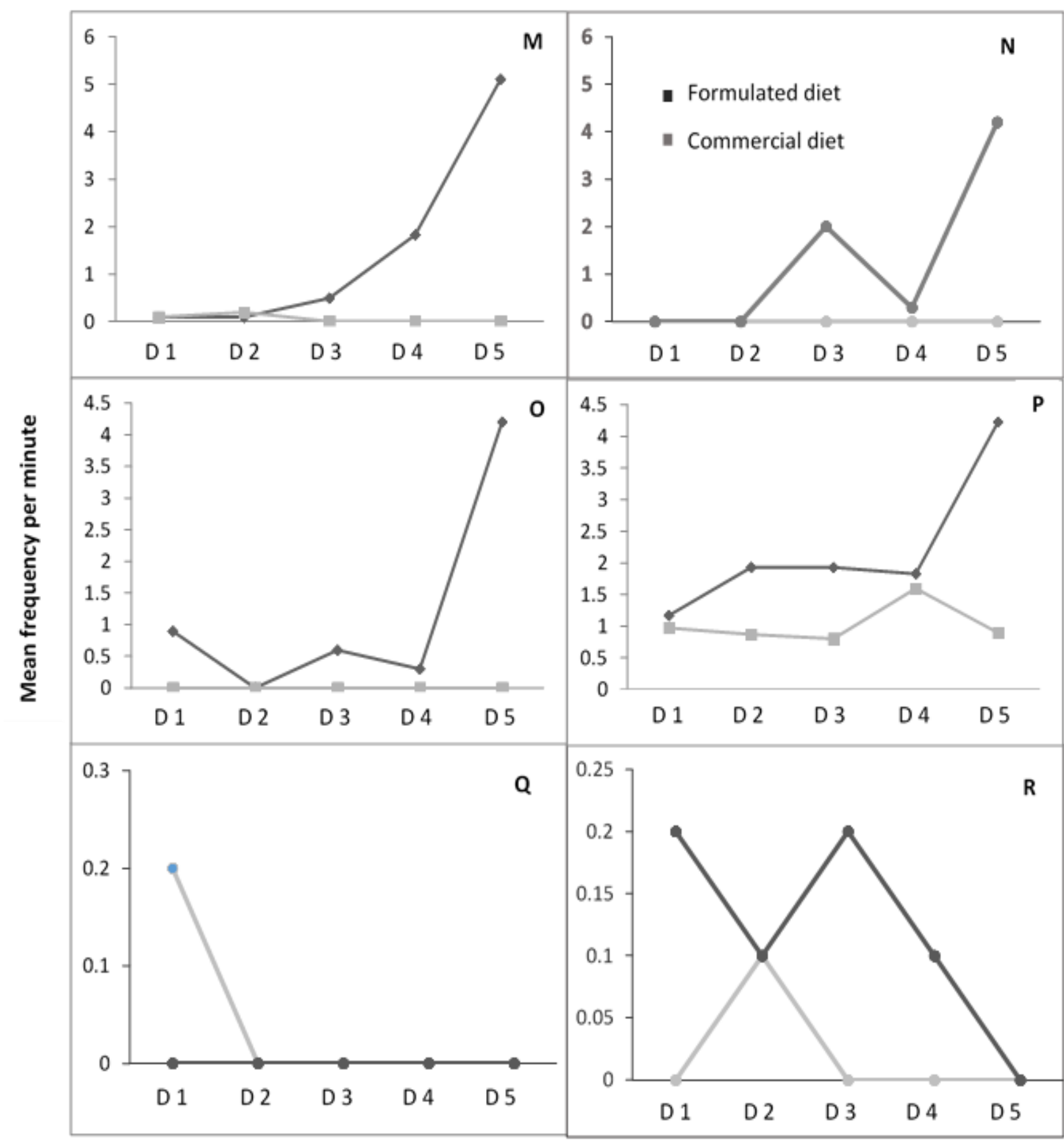

\section{Time ( $\mathrm{D}=$ Days)}

Figure 7. Social behaviour of cats fed with formulated diet and commercial diet $M=$ Foot contact, $N=$ Mouth open, $O=$ Paws up, $P=$ Approach contact, $Q=$ Face-off and $R=$ Stand-off 


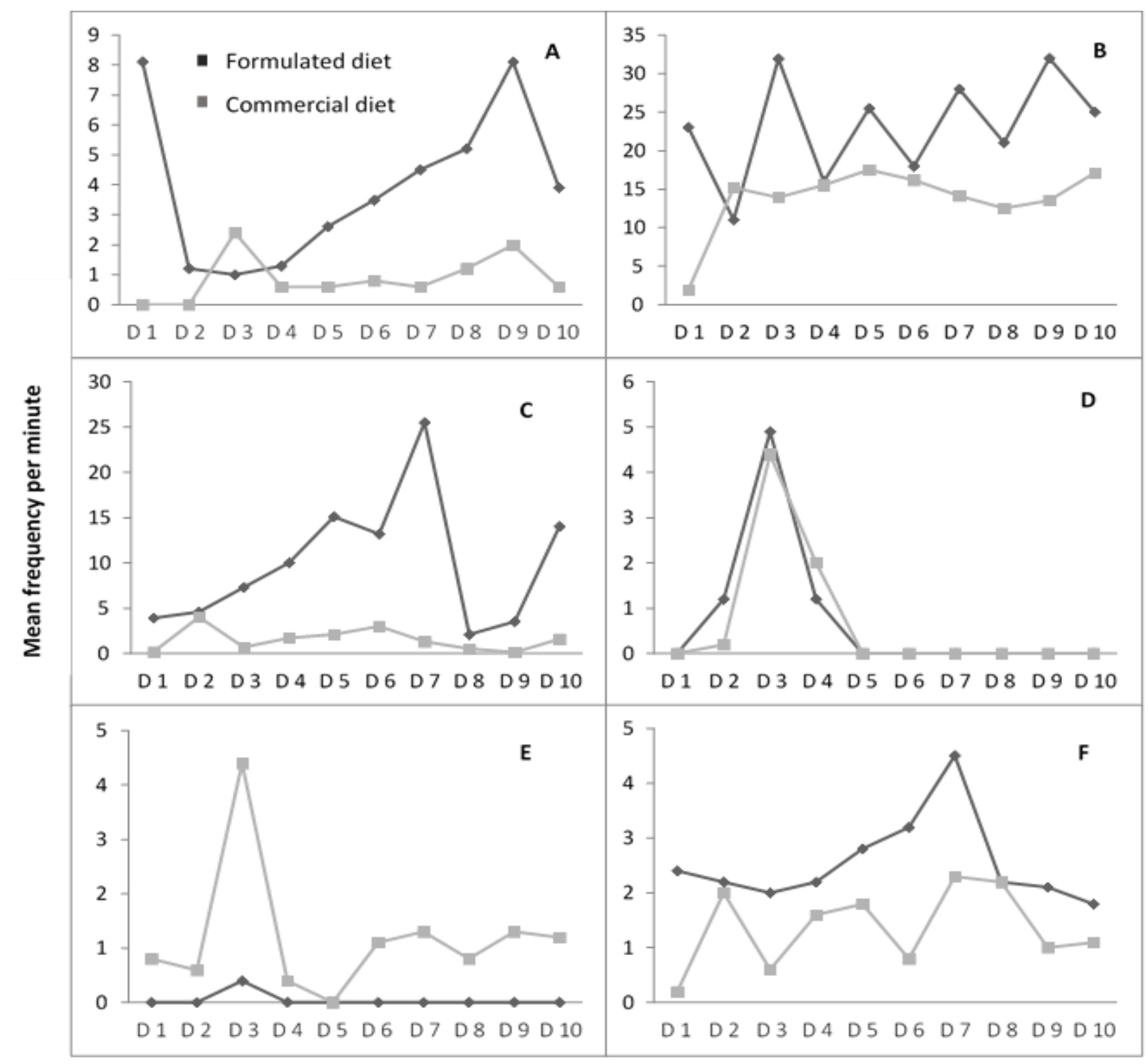

Time (D = Days)

Figure 8. Object play behaviour of cats fed with formulated diet and commercial diet $A=$ Arch, $B=$ Object contact,$C=$ Hold contact,$D=$ Rake, $E=$ Cry and $F=$ Stalk contact

The object play behaviours of felines are depicted in Figure 8. All object play behaviour categories showed significant differences between the diet groups $(\mathrm{p}<0.05)$.
Among the object play types, hold contact and rake play types showed similar mean frequencies. Behaviours in arch, object contact, cry and, stalk play types were significantly different for the two diet 
groups, and yet the mean frequencies indicated that the formulated diet group was highly active in arch, object contact and stalk play types. The commercial diet group was highly vocalized or cry in highly significant levels than the formulated diet group.

\section{CONCLUSION}

Both diets have similar effects on the growth rate of kittens while the formulated diet meets the required nutrient levels according to AAFCO standards. Social play behaviour of kittens fed with the formulated diet was higher than that of the kittens fed with commercial diet. Therefore, the formulated diet increased the level of activity in cats than the commercial diet. Some of the object play behaviours of cats fed with the formulated diet were higher compared to the cats fed with commercial diet. In general, the activity levels of kittens in two diet groups were same for object play. Hence, the formulated diet comprises a balanced nutritional profile that meets requirements for normal growth rates, skin and faecal sensory attributes and satisfying activity levels for cats.

\section{REFERENCES}

Association of American Feed Control Officials (AAFCO) (2009). Available from: http://www.aafco.org. [Accessed May 15, 2014]

Bateson, P. and Young, M. (1979). The influence of male kittens on the object play of their female siblings. Behavioural and Neural Biology,
27(3):374-378.

Bateson, P. and Young, M. (1981). Separation from the mother and the development of play in cats. Animal Behaviour, 29: 173-180.

Bateson, P., Michael, M. and Feaver, J. (1990). Play in the domestic cat is enhanced by rationing of the mother during lactation. Journal of Animal Behaviour, 40:514-525

Bradshaw J.W.S. and Cook, S.E. (2008). Patterns of pet cat behaviour at feeding occasions, Applied Animal Behavioural Science, 47:61-74.

Bradshaw, J.W.S., Rachel, A.C. and Brown, S.L. (2012). The Behaviour of the Domestic Cat ( $2^{\text {nd }}$ edition). CABI, Wallingford, Oxfordshire.

Bradstreet, R.B. (1954). Kjeldahl method for organic nitrogen. Analytical Chemistry, 26:85-187.

Caro, T.M. (1981). Sex differences in the termination of social play in cats. Journal of Animal Behaviour, 29:271279.

Global Pet Food Market (2014). Available from:http://www.marketresearch.com/ Consume r-Goods-c1596/ConsumerGoods-Retailing-c80/Pet-Foodc1885/. [Accessed July 22, 2014]

Linda, P. and Case, M.S. (2010). Canine and Feline Nutrition - A Resource for Companion Animal Professionals $\left(3^{\text {rd }}\right.$ edition), Elsevier, Maryland Heights, Missouri.

Martin, P. and Bateson, P. (1988). Behavioural Development in the Cat. In: Turner, D.C. and Bateson, P. (eds), The Domestic Cat: The Biology of its Behaviour. Cambridge University 
Press, Cambridge: 9-22

Miller, D.S. and Payne, P.R. (1959). A ballistic bomb calorimeter. British Journal of Nutrition, 13:501-508.

National Research Council (NRC) (2006).

Nutrient Requirements of Dogs and Cats, National Academy Press, Washington DC.

Pathfinder Report (2010). Global Pet Food Trends. Available from: http://www.gov.mb.ca/agriculture/mar ket-prices-and-statistics/trade statistics/pubs/canada_global_pet_foo d_trends_en.pdf. [Accessed 16 August 2014]

Thiex, N.J., Anderson, S. and Gildemeister, B. (2003). Crude fat, hexanes extraction, in feed, cereal grain, and forage. Journal of AOAC. 86:899-908. 